\title{
Using micro-computed tomography to examine the larynx in cases of suspected strangulation-a comparison of case findings and control images
}

\author{
Waltraud Baier $^{1} \cdot$ Brian A. Burnett ${ }^{2} \cdot$ Mark Payne $^{3} \cdot$ Jason M. Warnett ${ }^{1} \cdot$ Mark A. Williams $^{1}$
}

Received: 4 April 2019 / Accepted: 22 October 2019 / Published online: 12 November 2019

(C) The Author(s) 2019

\begin{abstract}
The examination of strangulation is one of the most challenging causes of death diagnoses encountered in forensic pathology. The injuries are often subtle and difficult to detect, especially in cases that lack superficial marks. Fractures of the laryngeal skeleton are commonly regarded as evidence of strangulation but these can be too subtle to be detected during autopsy. Micro-CT is a novel imaging technique that achieves a spatial resolution $1 \mu \mathrm{m}$ or less which lends itself to the examination of small and delicate structures such as the larynx. However, there is little information to date regarding the appearance of the larynx at this scale, thus complicating the interpretation of the micro-CT images. This study therefore uses micro-CT to examine ten larynges from strangulation deaths and to compare them to nineteen samples from donor individuals in order to distinguish between naturally occurring features and actual trauma. It was found that there are several features which mimic damage in the donor group. Using associated case information, initial trends and patterns of different strangulation methods were established.
\end{abstract}

Keywords Micro-computed tomography $\cdot$ Forensic Imaging $\cdot$ Strangulation $\cdot$ Larynx

\section{Introduction}

Strangulation is the third most common homicide method in the UK, although women are even more likely to become a victim due to intimate partner violence $[1,2]$. Despite the

Waltraud Baier

val.baier@warwick.ac.uk

Brian A. Burnett

brian.burnett@uhcw.nhs.uk

Mark Payne

m.payne@west-midlands.pnn.police.uk

Jason M. Warnett

j.m.warnett@warwick.ac.uk

Mark A. Williams

m.a.williams.1@warwick.ac.uk

1 WMG, International Manufacturing Centre, University of Warwick, Coventry CV4 7AL, UK

2 UHCW NHS Trust, Coventry CV2 2DX, UK

3 West Midlands Police, B4 6NQ, Birmingham, UK frequent occurrence of such cases, the diagnosis of strangulation in forensic pathology is still predominantly one of exclusion, in particular if there is a lack of distinctive signs such as petechial bleeding or bruising of the soft tissues of the neck. Fractures of the laryngeal cartilages or the hyoid bone are considered evidence for strangulation but they can have other causes such as sports injuries, motor vehicle accidents or falls [3]. Such fractures tend to be associated with haemorrhages, but absence thereof can make subtle injuries even more difficult to detect at the risk of potentially missing them during autopsy. In some cases, histological examination is conducted to examine fractures identified at postmortem to assess the timing of the injury in relation to time of death [4]. This process is destructive, time consuming and costly. With advances in technology, new ways of dealing with this issue have emerged with many researchers advocating the use of computed tomography $(\mathrm{CT})$ to study laryngeal trauma $[5,6]$. Even more recently, initial studies have explored the use of microcomputed tomography (micro-CT) to examine such cases in order to identify micro-fractures which might not be visible on medical CT or postmortem examination [7, 8]. Micro-CT has proven successful in a number of different forensic applications such as toolmark analysis [9-11], gunshot wound 
analysis [12, 13] and forensic entomology [14]. However, all of the existing literature on using micro-CT for laryngeal trauma analysis is based on casework; no comparative studies exist to date to the authors' knowledge. This study aims to address this void as it draws on an unprecedented database of micro-CT scans of larynges from strangulation cases as well as from natural deaths. The injuries observed in the former group were compared with those in the latter control group of uninjured larynges from donor individuals in order to assess which features can occur in the normal population. Studies by Tsai et al. [15] and Baier et al. [16] have compared micro-CT to histology, the current gold standard for forensic injury analysis, and found the method to be reliable for injuries in bone. Method validation is becoming an increasing concern in forensic science and while micro-CT had been validated in industrial settings [17-19] where the method as such has been proven to work, it has not been systematically tested for forensic purposes. This study forms an exploratory study to inform future more structured validation studies.

\section{Materials and methods}

\section{Micro-CT}

The overall principles of micro-CT are similar to medical $\mathrm{CT}$ as it uses a stack of $2 \mathrm{D}$ radiographs to examine the internal structure of a sample, but it allows a spatial resolution, or voxel size, of approximately $40 \mu \mathrm{m}$ for a sample of the size of a larynx. The source and detector of a typical lab-based micro-CT machine are stationary during the scan with the sample on a rotating stage at the centre. Radiographs are acquired at every degree angle through a full $360^{\circ}$ rotation and later reconstructed to form the $3 \mathrm{D}$ model of the object [20].

All samples were scanned using a Nikon 225/320 LC micro-CT scanner (Nikon Metrology, Tring, UK) and reconstructed using the system's proprietary software CTPro. Typical scan parameters were

$120 \mathrm{kV}, 135 \mu \mathrm{A}, 500-\mathrm{ms}$ exposure, 24-dB gain, no filtration, creating 3141 projections, although some adjustments were made where necessary. The scan images were visually inspected in VG Studio MAX 2.2 (Volume Graphics, Heidelberg, Germany).

Two groups of larynges were examined. The first consisted of ten samples from forensic strangulation cases. Only cases where strangulation had been confirmed through multiple lines of enquiry (witness statements, confessions, CCTV, forensic post-mortem) were considered in this group; no inconclusive cases were included (age range 20-68 years; male 4, female 6). The second group consisted of nineteen control samples from donor individuals with no recorded history of laryngeal trauma (age range 46-94 years; male 12, female 7). Only the thyroid cartilage and the hyoid were considered for this study. Full demographic details are provided in Appendix Tables 1 and 2.

The examination criteria were determined from the control group as potentially misleading features during analysis. These were circular defects within the ossified cartilage, fragmented appearance of ossified material, incomplete fusion of the hyoid elements, abrupt angles and linear grooves within the ossified cartilage, and the presence of triticeous cartilages. Based on the literature, the presence, completeness (incomplete, complete, displaced) and location of fractures were also included as a criterion as they are frequently encountered in strangulation deaths. In order to include all possible fracture origins, they were termed discontinuities in the analysis. An example for each category is shown in Fig. 1.

The postmortem findings were also noted for the forensic cases. They were summarised as superficial (petechiae, facial congestion, bruising on the neck, ligature marks) and internal (haemorrhage/bruising on the muscles and soft tissues of the neck). The mode of strangulation (manual, ligature, chokehold) was noted where sufficient evidence was available.

\section{Results}

The full results are provided in Appendix Table 1 (strangulation group) and Appendix Table 2 (control group). Triticeous cartilages were observed in $30 \%$ of cases in the strangulation group $(n=3)$, and in $47 \%$ in the control group $(n=9)$, their appearance being the same in both groups with smooth cortical bone and a spherical to oval shape. Abrupt angles are seen along the superior thyroid margins, the superior thyroid horns, and the greater horns of the hyoid in $10 \%$ of cases in the strangulation group $(n$ $=1)$, and $32 \%$ of cases in the control group $(n=6)$. Circular holes within the ossified cartilage occurred in $40 \%$ of strangulation cases $(n=4)$, and $32 \%$ of control cases $(n=6)$, they all display clear and regular margins. Linear grooves were only observed on the posterior aspect (including superior and inferior horns) of the ossified thyroid cartilage (50\% or $n=5$ in strangulation group, $32 \%$ or $n=6$ in control group). They predominantly extend vertically along the posterior margin although some are observed on the lateral aspects of the posterior margin.

Figure 2 illustrates the observation that the forensic cases show discontinuities in three different locations (left and right side were counted as one) whereas there is only one feature location in the control group, on $16 \%$ of cases $(n=3)$. Discontinuities at this location were observed in $40 \%$ of the forensic samples $(n=4)$, two of which 
Fig. 1 Some of the assessment features described in this study. a Circular "hole" within the ossified cartilage and fragmentary ossification, S172809. b Unusual angles of the greater horns (hyoid) and superior horns (thyroid cartilage), S173160. c Incomplete fusion of the greater horn and body of the hyoid, S170345. d Linear crease-like furrow or groove along the posterior margins of the thyroid cartilage, S170452
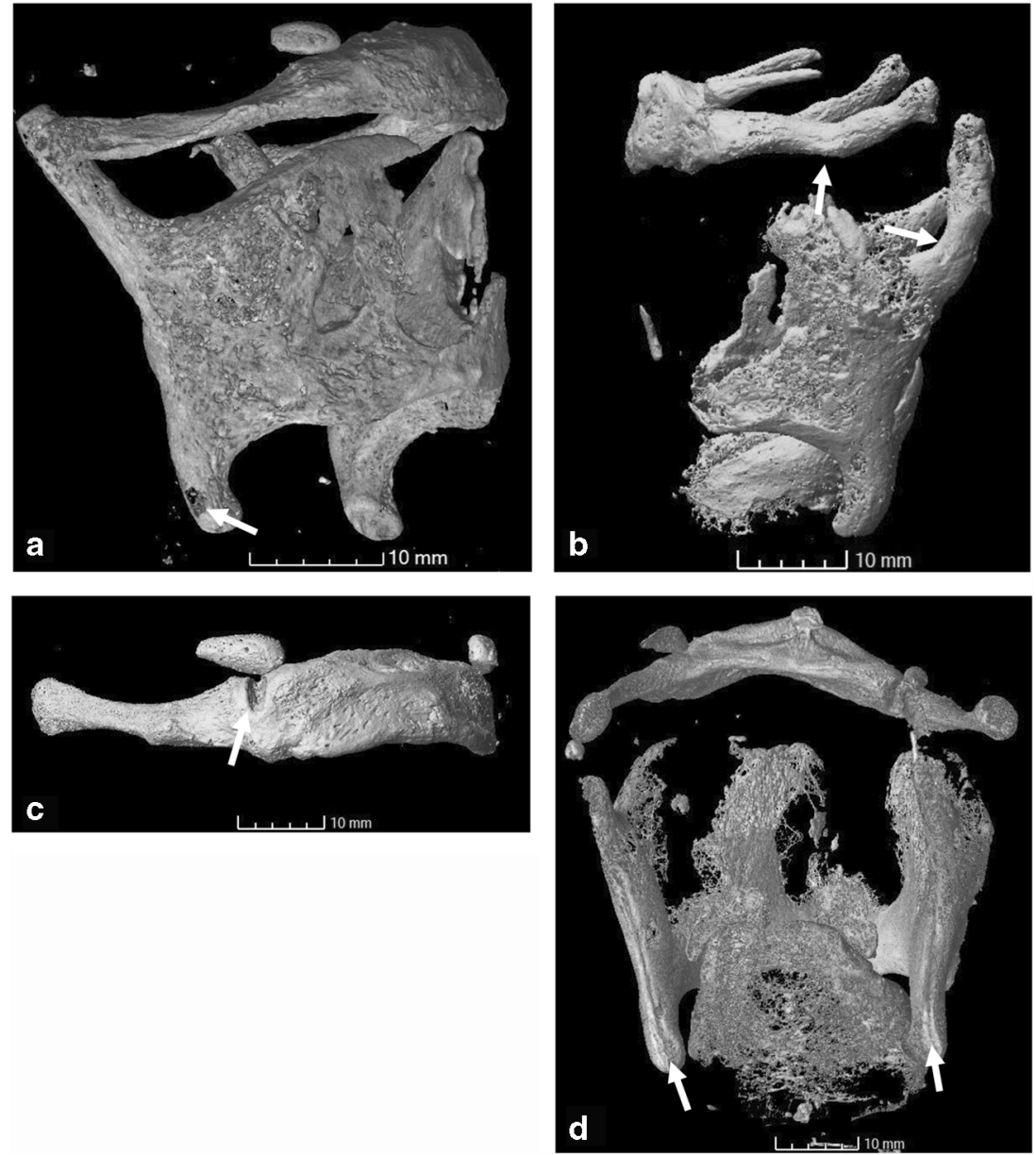

displayed a discontinuity left and right of the midline. Seventy percent of the forensic cases $(n=7)$ displayed a discontinuity on the superior thyroid horns with the base being the most affected area. Of these, six cases displayed bilateral discontinuities (total number of discontinuities $n$ = 13). The inferior thyroid horns were only affected in two cases $(20 \%)$. The three cases $(30 \%)$ where the hyoid bone was fractured were all caused by ligature strangulation.

\section{Discussion}

\section{Significance of the results}

Discontinuities The most likely explanation for the fracturelike discontinuity on the inferior thyroid margin, observed in both groups, is a product of the natural ossification process. While they appear like fractures on the volume-rendering, on the $2 \mathrm{D}$ sections the edges of the discontinuity appear rounded
Fig. 2 Typical locations of discontinuities identified in this study (arrows). a Discontinuity on the inferior thyroid margin of sample S172809 in the control group. b Fracture at the base of the superior thyroid horns of the forensic case OP Isengard
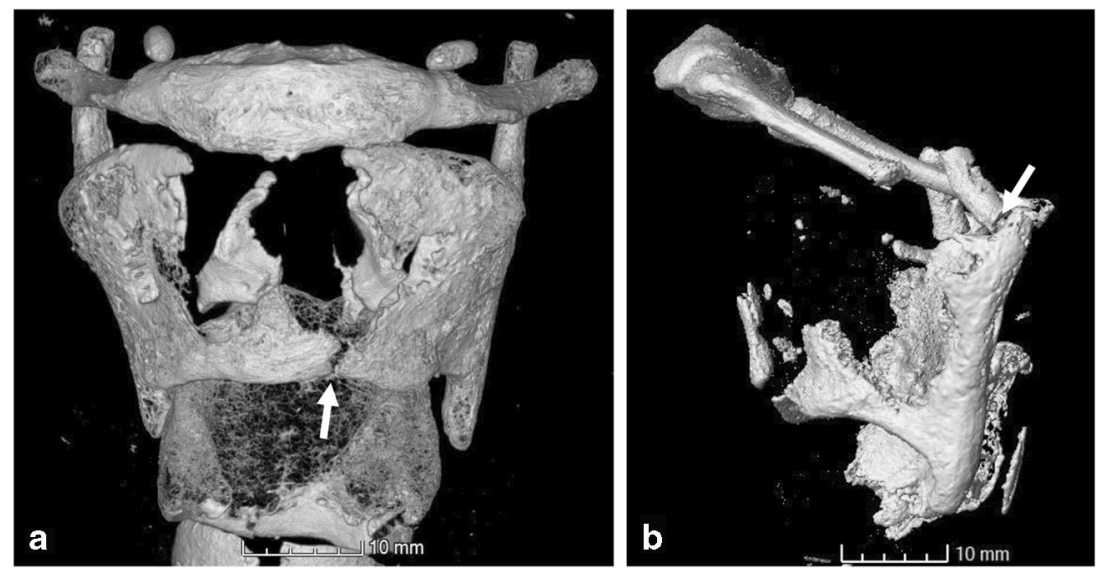
and uninterrupted. All other discontinuities, exclusively encountered in the forensic group, are considered true fractures as they display sharper edges with interrupted cortical bone and trabeculae. Hyoid fractures have only been observed in the posterior third of the greater horn where the bone is delicate and thin. The greater horn has been observed as a common fracture location in several other studies of neck compression $[3,5]$ and appears to be strong support for compression of the neck. All the fractures of the greater horns of the hyoid occurred in ligature strangulations. This contradicts the review by Dettmeyer et al. [21] who found hyoid fractures to be more common in manual strangulations. The majority of superior thyroid horn fractures occur bilaterally. Only one of those bilateral injuries was not a ligature strangulation. However, there were also cases of ligature strangulation which did not result in bilateral fractures. This is a recurring dilemma in interpreting strangulation deaths that there is much overlap in the injury pattern. Many studies have attempted to classify injuries according to the mode of strangulation [22-24] and while there are some trends there is also overlap which warrants caution not to solely rely on fracture patterns for the interpretation.

Circular holes Smooth-edged circular holes were only seen in the thyroid cartilage but were not restricted to a specific location. Their occurrence within the laminae is a common location for the thyroid foramen which serves as an opening for vessels or nerves [25]. It is possible that the circular openings in other locations fulfil a similar purpose or simply represent ossification irregularities. Their presence in the control group supports an interpretation as a natural cause as opposed to possible fingertip damage.
Fragmentation The ossified cartilages in the forensic group appeared more fragmented than those in the control group (Fig. 3). This manifested as an increased number of small pieces of ossified material that did not form a coherent structure. However, this could be explained by younger age of individuals in this group. The more advanced age of the donor individuals in the control group is reflected by the more advanced stages of ossification. Nonetheless, the appearance of the loose fragments was similar in both groups. Individual ossified "nodules" displayed rounded edges. While the majority of fragments in the control group are found along the margins of the thyroid laminae, the case examples display fragments in all locations. As they are similar in appearance, they are not considered to be compelling evidence of trauma. No other study has examined this feature at this level of detail to the authors' knowledge, further comparison will therefore depend on a future expansion of this database.

Incomplete fusion The fusion or non-fusion of the greater horns to the body of the hyoid bone is an easily misinterpreted feature. While it is well-established in the literature that these elements can fuse over time [26, 27], in pathological practise hypermobility is sometimes taken as evidence of a hyoid fracture [4]. Depending on the pathologist's sensitivity and experience, a natural nonunion could be mistaken for trauma. Radiologically, a narrow gap between the body and greater horn or incomplete fusion of the two parts might be mistaken as a fracture. The control group has shown several examples of incomplete fusion with a narrow gap still visible at the body-greater horn junction, see Fig. 4 for a transverse section and the volume-rendering of the scan. Both sides
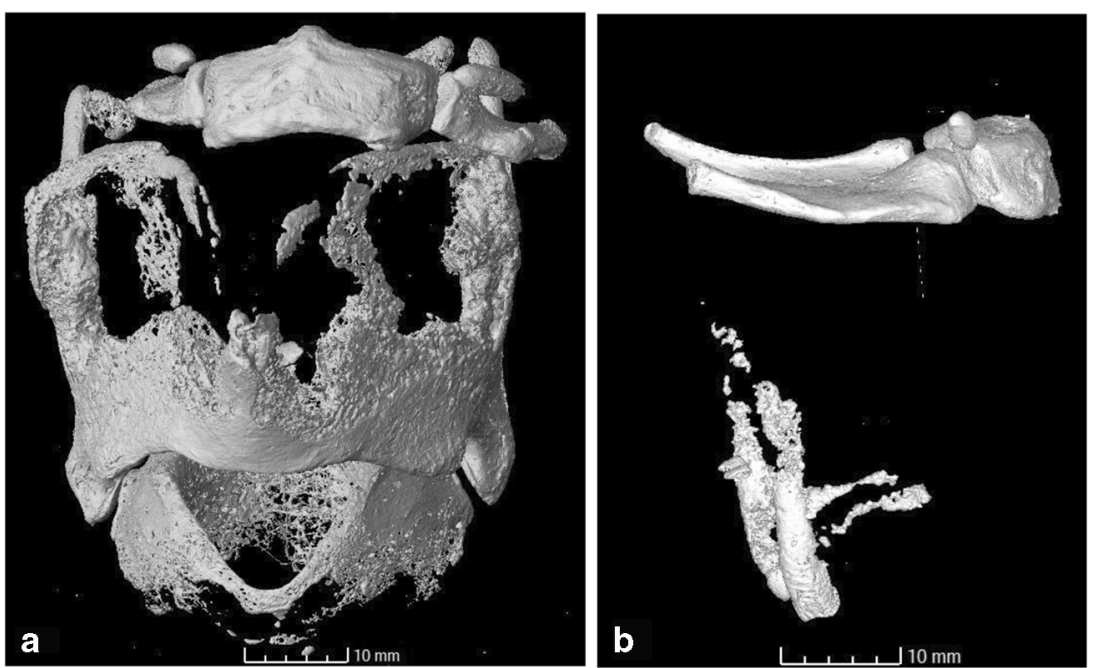

Fig. 3 Different stages of laryngeal cartilage ossification. The control group was composed of generally older individuals than the forensic group, displaying more advanced stages of ossification and therefore a different pattern of fragmentation. a Sample S170405, showing some fragmentation along the anterior margins of the thyroid laminae. b OP Aporia, the individual's younger age (early 20s) is reflected in the limited ossification and higher degree of fragmentation along the posterior and inferior margins of the thyroid cartilage 

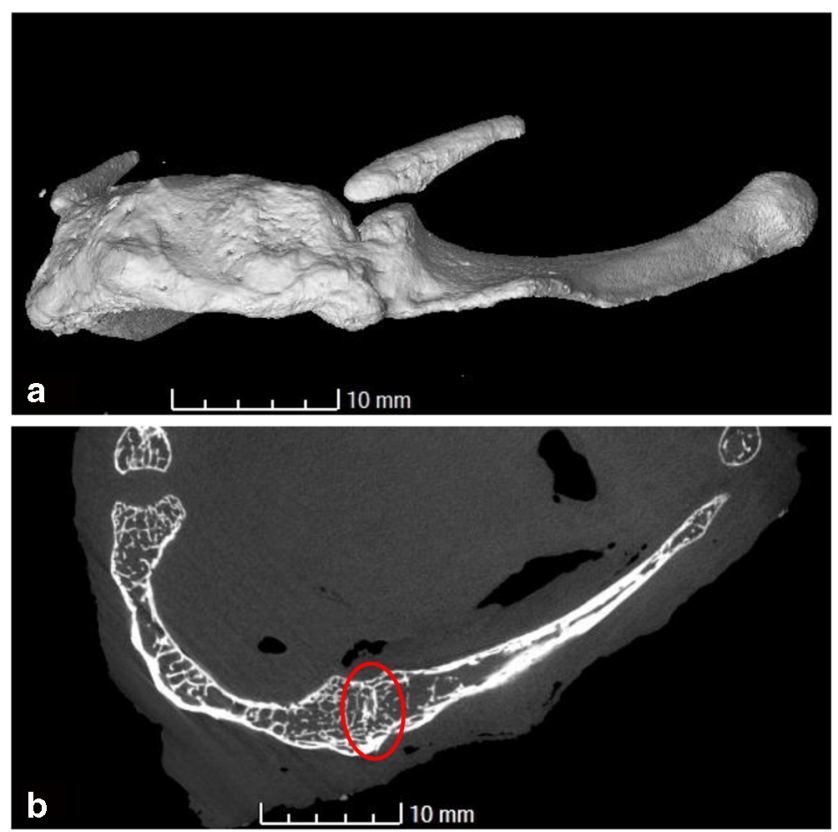

Fig. 4 Incomplete fusion of the left greater horn and the body of the hyoid in control sample S171263. a Volume rendering showing a bony bridge across the two elements. b Transverse section through the specimen at the location of the bridge. The area of fusion still displays some of the original cortical bone surfaces which are gradually being resorbed (circled area)

display an uninterrupted cortical bone surface which only begins to disappear after fusion has completed. No actual fractures were observed at this location in either group.

Abrupt angles These were encountered frequently in the control group, often on the superior thyroid horns and along the superior margins of the thyroid laminae. In one control sample, the greater horns of the hyoid were angled upwards in the posterior third. These angles are present in the normal population but from this study it does not become clear whether they are due to normal variation or previous, healed trauma. A study by Maxeiner [28] found that healed fractures of the hyoid and thyroid cartilage can be found amongst alcoholics who are prone to frequent falls or accidents. However, information about the donors' lifestyles was not available in the present study.

Linear grooves These features resemble fine fissures or creases when seen on the $3 \mathrm{D}$ volume-rendered scan, shown in Fig. 2D. Using the 2D sections helped identifying them as superficial. They were frequently observed in the control group which is important to avoid misinterpretation as real fractures in the forensic samples. The location and orientation of these creases differed from the actual fractures observed (vertical as opposed to approximately horizontal). This feature in particular has only been made possible to study through the increased detail

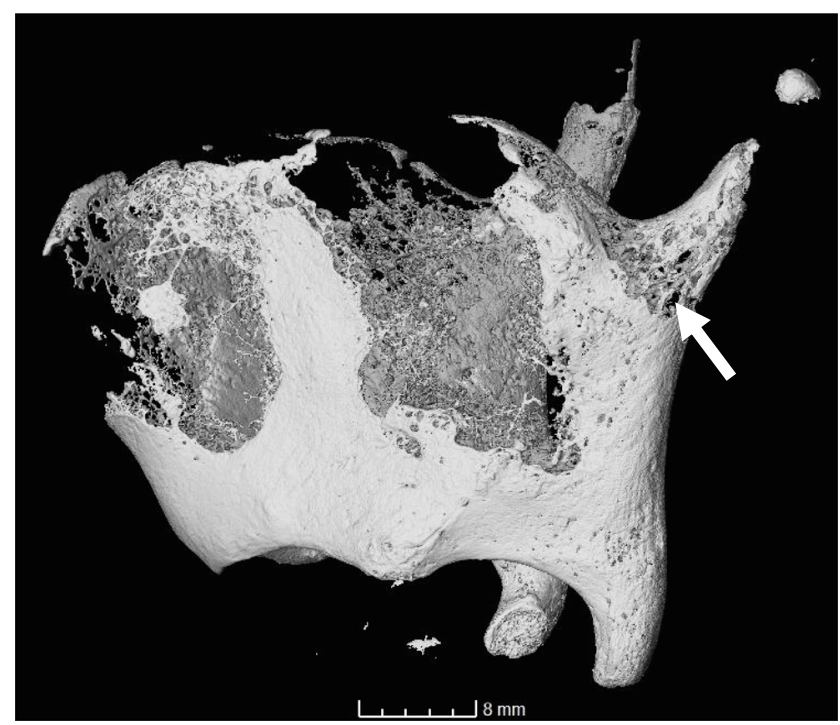

Fig. 5 Different ossification within the same specimen (S170452). The area at the base of the superior thyroid horn (arrow) is less densely ossified than the surrounding areas. This contrast might affect the fracture potential at this location

of micro-CT and has not been described previously.A similar feature was a sharp crest running in no particular direction, possibly indicating the ossification "front". One side of this crest displays a cortical bone surface whereas the other side displays less solidly ossified material, shown in Fig. 5 for control sample S170452. When examining the volume rendering of a scan, the shadow created by the crest can mimic a fracture line. Having seen this feature in numerous control cases serves as reassurance that this is a natural feature. This was most commonly observed in the area at the base of the superior thyroid horns. The horns and the posterior margins displayed more densely ossified material compared to the more loosely structured trabeculae at the base of the horns. This contrasting ossification pattern is important to understand as it might impact laryngeal fractures. Saternus et al. [29] argue that the differences in ossification density create weak links which are then more prone to fracturing. A fracture in these areas would therefore not be unexpected and potentially requires less force than in other areas or if ossification there was more homogenous. The base of the superior thyroid horns was frequently seen as less densely ossified in the control group and fractured in the strangulation group, supporting this theory.

Triticeous cartilages These have occasionally been observed in the literature on normal anatomical variation of the larynx [26]. These small spherical ossifications are found in the thyrohyoid membrane which connects the superior thyroid horns to the posterior greater horns of the hyoid. The close proximity to the superior thyroid 
horns poses the risk of misinterpreting them as fragments of the horns, in particular if the soft tissue structures have not been visualised sufficiently to allow a distinction or if their natural position has been disturbed by the dissection process. The main difference to fragments of the superior thyroid horns is that the triticeous cartilages appear rounded with a smooth cortical surface whereas horn fragments have at least one irregular aspect.

\section{General discussion}

It becomes immediately obvious that the spatial resolution of micro-CT affects the appearance of the ossified laryngeal structures compared to hospital CT. This applies in particular to the volume rendered images, as seen in the illustrations used by Dang-Tran et al. [30] who used medical CT to study the ossification process of the laryngeal cartilages. Micro-CT scans show individual trabeculae and their connective structure while the medical CT scans show these structures only as less welldefined rounded surfaces which has the clear potential to miss subtle fractures. This justifies conducting this study in order to understand this new level of detail and the potential for injury detection the method offers. Studies such as the present one also form an important part of the overall method validation which is elementary to the admission of any new method as evidence before a court of law. In the US, the Daubert standards outline that new methods need to be tested (Daubert v Merrell Dow Pharmaceuticals, Inc 509 U.S.579 (1993)); in the UK, this falls under the guidelines set out by the Forensic Science Regulator [31]. The FSR's role is to ensure that forensic science practitioners adhere to strict quality standards such as using only validated and verified methods, detailed in the Code of Practise [30]. The FSR does not currently hold statutory powers, but these requirements have also been included in the Criminal Procedure Rules (2015) which are legally binding. They serve to direct courts towards more rigorous scrutiny of forensic science evidence in order to reduce the risk of wrongful convictions to which flawed forensic science has contributed significantly in the past [32]. The present study provides initial image data for both injured and uninjured larynges. This does not yet constitute full validation but rather a prerequisite to design future validation studies as it provides fundamentals of what to expect from such scans. Ultimately, adding new information about minute details of the larynx it aims to provide a more solid knowledge foundation onto which expert witnesses can base their interpretation of strangulation deaths, thus increasing the overall evidence quality. However, due to the normal anatomical variation of the human larynx, more control samples can be sourced to further study these features and establish a rigorous validation process. Such a process would include histological assessment of all the fractures and fracture-mimicking features identified in the control group to verify these. Some of the forensic cases have subsequently been examined histologically as part of the criminal investigation but the features identified on the micro-CT images were not sectioned systematically. Previous research suggests that there is a close match between micro-CT and histology for samples including larynges [16], adding credibility to the present findings. The lack of a systematic comparison with histology could be considered a limitation of the present study. This study has identified many features not previously described in the literature, developing suitable terminology therefore relied solely on the appearance in the micro-CT images.

\section{Conclusion}

This study has demonstrated the importance of studying a control population for comparison when introducing a new method into the forensic examination of strangulation deaths. Some of the features observed on the forensic samples, in particular the discontinuities on the inferior thyroid margin, might be misinterpreted as trauma had they not been seen as naturally occurring in the control group. True fractures were only observed on the posterior aspect of the thyroid cartilage and hyoid bone. Misinterpretation of these features could have dramatic consequences if someone was wrongfully convicted of murder based on such findings, thus making future validation studies based on the present results inevitable.

Acknowledgements We would like to express our gratitude to the International Society of Forensic Radiology and Imaging (ISFRI) who provided us with the opportunity to present the preliminary results of this study at their annual conference in Melbourne in May 2018. This presentation received the inaugural ISFRI prize for young researchers.

\section{Compliance with ethical standards}

Conflict of interest This research was conducted as part of a PhD studentship funded by West Midlands Police. Initial results were presented at the International Society of Forensic Radiology and Imaging annual conference, Melbourne May 2018, and received the ISFRI prize.

Ethical approval All procedures performed in studies involving human participants were in accordance with the ethical standards of the institutional and/or national research committee (University of Warwick Biomedical and Scientific Research Council, REGO-2016-1761) and with the 1964 Helsinki declaration and its later amendments or comparable ethical standards.

Informed consent Informed consent was obtained from all individual participants included in the study. Consent was assumed for homicide victims as the work was conducted as part of the criminal investigation. 


\section{Appendix}

Table 1 Features and their location observed in the suspected strangulation cases along with the autopsy findings

\begin{tabular}{|c|c|c|c|c|c|c|c|}
\hline Case & Sex & Age & Feature location & Feature type & Superficial marks & Internal marks & Mode of strangulation \\
\hline Aponi & $\mathrm{F}$ & 35 & $\begin{array}{l}\mathrm{R} \text { sup horn } \\
\mathrm{L}+\mathrm{R} \text { inf thyroid horns } \\
\text { Sup thyroid margins } \\
\mathrm{R} \text { post thyroid margin }\end{array}$ & $\begin{array}{l}\text { Complete fracture } \\
\text { Circular hole } \\
\text { Fragmentary ossification } \\
\text { Linear crease }\end{array}$ & Yes & Yes & Unknown \\
\hline Albatross & M & 32 & $\begin{array}{l}\text { L sup horn } \\
\mathrm{R} \text { sup horn } \\
\mathrm{R} \text { of ant midline inf thyroid margin } \\
\mathrm{L} \text { of ant midline inf thyroid margin } \\
\text { Laminae } \\
\text { L Lamina }\end{array}$ & $\begin{array}{l}\text { Displaced fracture } \\
\text { Complete fracture } \\
\text { Incomplete fracture } \\
\text { Incomplete fracture } \\
\text { Fragmentary ossification } \\
\text { Circular hole }\end{array}$ & Yes & Yes & Ligature \\
\hline Bulblet & M & 71 & $\begin{array}{l}\text { L greater horn } \\
\text { R sup horn } \\
\text { R greater horn } \\
\text { R }\end{array}$ & $\begin{array}{l}\text { Complete fracture } \\
\text { Incomplete fracture } \\
\text { Abrupt angle } \\
\text { Triticeous cartilage }\end{array}$ & Yes & Yes & Ligature \\
\hline Catni & $\mathrm{F}$ & 61 & $\begin{array}{l}\mathrm{R} \text { of ant midline inf thyroid margin } \\
\mathrm{L} \text { post thyroid margin } \\
\mathrm{L} \text { base sup thyroid horn }\end{array}$ & $\begin{array}{l}\text { Complete fracture } \\
\text { Linear crease } \\
\text { Linear crease }\end{array}$ & Yes & No & Unknown \\
\hline Chaucer & M & 20 & $\begin{array}{l}\mathrm{L} \text { inf horn } \\
\mathrm{R} \text { inf horn } \\
\text { Post thyroid margins }\end{array}$ & $\begin{array}{l}\text { Complete fracture } \\
\text { Complete fracture } \\
\text { Fragmentary ossification }\end{array}$ & Yes & Yes & Chokehold \\
\hline Isengard & $\mathrm{F}$ & 37 & $\begin{array}{l}\text { L sup horn } \\
\text { R sup horn } \\
L+R \text { post thyroid margins }\end{array}$ & $\begin{array}{l}\text { Displaced fracture } \\
\text { Displaced fracture } \\
\text { Linear crease }\end{array}$ & Yes & Yes & Unknown \\
\hline Marshside & $\mathrm{F}$ & 51 & $\begin{array}{l}\mathrm{R} \text { greater horn } \\
\mathrm{R} \text { inf horn }\end{array}$ & $\begin{array}{l}\text { Complete fracture } \\
\text { Incomplete fracture }\end{array}$ & Yes & No & Ligature \\
\hline Pencil & M & 59 & $\begin{array}{l}\mathrm{R} \text { greater horn } \\
\mathrm{L} \text { greater horn } \\
\mathrm{R} \text { of ant midline inf thyroid margin } \\
\mathrm{R} \text { sup horn } \\
\mathrm{L} \text { sup horn } \\
\text { Sup thyroid laminae } \\
\mathrm{L}+\mathrm{R} \\
\mathrm{L}+\mathrm{R} \text { post thyroid margins }\end{array}$ & $\begin{array}{l}\text { Complete fracture } \\
\text { Complete fracture } \\
\text { Incomplete fracture } \\
\text { Incomplete fracture } \\
\text { Incomplete fracture } \\
\text { Fragmentary ossification } \\
\text { Triticeous cartilages } \\
\text { Linear crease }\end{array}$ & Yes & Yes & Ligature \\
\hline Platte & $\mathrm{F}$ & 68 & $\begin{array}{l}\text { L sup horn tip } \\
\text { R sup horn } \\
\text { L sup horn base } \\
\text { L of ant midline inf thyroid margin } \\
\text { Laminae } \\
\text { L Lamina } \\
\text { R greater horn }\end{array}$ & $\begin{array}{l}\text { Displaced fracture } \\
\text { Displaced fracture } \\
\text { Complete fracture } \\
\text { Complete fracture } \\
\text { Fragmentary ossification } \\
\text { Circular hole } \\
\text { Incomplete fusion }\end{array}$ & Yes & Yes & Ligature \\
\hline Syringe & $\mathrm{F}$ & 48 & $\begin{array}{l}\text { R sup horn } \\
\text { L sup horn } \\
R \\
\text { L + R sup thyroid horns } \\
\text { R inf thyroid horn } \\
\text { R lateral post thyroid margin }\end{array}$ & $\begin{array}{l}\text { Displaced fracture } \\
\text { Displaced fracture } \\
\text { Triticeous cartilage } \\
\text { Fragmentary ossification } \\
\text { Circular hole } \\
\text { Linear crease }\end{array}$ & Yes & Yes & Manual and ligature \\
\hline
\end{tabular}


Table 2 Features and their location observed in the control group, along with demographic details and cause of death as provided by the tissue supplier

\begin{tabular}{|c|c|c|c|c|c|}
\hline Specimen & Sex & Age & Feature location & Feature type & Cause of death \\
\hline S170459 & $\mathrm{F}$ & 81 & $\begin{array}{l}\mathrm{R} \text { of ant midline inf thyroid margin } \\
\mathrm{L}+\mathrm{R} \text { Lamina } \\
\text { Sup thyroid margins } \\
\text { Ant lamina }\end{array}$ & $\begin{array}{l}\text { Complete fracture } \\
\text { Circular hole } \\
\text { Fragmentary ossification } \\
\text { Fragmentary ossification }\end{array}$ & Lung cancer \\
\hline S173045 & $\mathrm{F}$ & 70 & $\begin{array}{l}\mathrm{R} \text { of ant midline inf thyroid margin } \\
\text { Laminae } \\
\text { L lamina }\end{array}$ & $\begin{array}{l}\text { Complete fracture } \\
\text { Fragmentary ossification } \\
\text { Circular hole }\end{array}$ & Breast cancer \\
\hline S172809 & $\mathrm{F}$ & 93 & $\begin{array}{l}\mathrm{L} \text { of ant midline inf thyroid margin } \\
\mathrm{R} \text { inf thyroid horn }\end{array}$ & $\begin{array}{l}\text { Complete fracture } \\
\text { Circular hole }\end{array}$ & OP Complications \\
\hline S170452 & M & 73 & $\begin{array}{l}\mathrm{L}+\mathrm{R} \\
\text { Sup margins laminae } \\
\mathrm{L}+\mathrm{R} \text { post thyroid margins }\end{array}$ & $\begin{array}{l}\text { Triticeous cartilages } \\
\text { Fragmentary ossification } \\
\text { Linear crease }\end{array}$ & Lymphoma \\
\hline S170445 & M & 80 & $\begin{array}{l}\mathrm{L}+\mathrm{R} \\
\mathrm{L}+\mathrm{R} \text { post thyroid margins }\end{array}$ & $\begin{array}{l}\text { Triticeous cartilages } \\
\text { Linear crease }\end{array}$ & Respiratory failure \\
\hline S170320 & M & 75 & $\begin{array}{l}\mathrm{L}+\mathrm{R} \\
\mathrm{L} \text { post thyroid margin }\end{array}$ & $\begin{array}{l}\text { Triticeous cartilages } \\
\text { Linear crease }\end{array}$ & Myeolodysplastic Syndrome \\
\hline S170167 & M & 90 & $\begin{array}{l}\mathrm{L}+\mathrm{R} \\
\text { Post thyroid margins } \\
\mathrm{L}+\mathrm{R} \text { Laminae }\end{array}$ & $\begin{array}{l}\text { Triticeous cartilages } \\
\text { Abrupt angles } \\
\text { Circular holes }\end{array}$ & Pulmonary Fibrosis \\
\hline S170163 & M & 46 & $\begin{array}{l}\text { Sup margins laminae } \\
\text { Sup thyroid horns } \\
L+R\end{array}$ & $\begin{array}{l}\text { Fragmentary ossification } \\
\text { Fragmentary ossification } \\
\text { Triticeous cartilages }\end{array}$ & Renal disease \\
\hline S170105 & $\mathrm{F}$ & 86 & $\begin{array}{l}\text { Ant midline } \\
\text { L Lamina } \\
L+R \text { lateral sup thyroid horns }\end{array}$ & $\begin{array}{l}\text { Fragmentary ossification } \\
\text { Circular hole } \\
\text { Linear crease }\end{array}$ & Cerebrovascular accident \\
\hline S173160 & $\mathrm{F}$ & 75 & $\begin{array}{l}\text { Sup thyroid horns } \\
\text { Greater horns } \\
\text { Ant and sup laminae }\end{array}$ & $\begin{array}{l}\text { Abrupt angles } \\
\text { Abrupt angles } \\
\text { Fragmentary ossification }\end{array}$ & Neoplasm of the lung \\
\hline S173053 & M & 79 & L sup thyroid horn & Abrupt angle & Lymphoma \\
\hline S173046 & M & 88 & $\begin{array}{l}\text { L sup thyroid horn } \\
\text { Laminae } \\
\text { R sup thyroid margin }\end{array}$ & $\begin{array}{l}\text { Circular hole } \\
\text { Fragmentary ossification } \\
\text { Abrupt angle }\end{array}$ & Coronary Artery Disease \\
\hline S172982 & M & 88 & $\begin{array}{l}\text { Sup thyroid margins } \\
\text { Sup thyroid margins }\end{array}$ & $\begin{array}{l}\text { Fragmentary ossification } \\
\text { Abrupt angles }\end{array}$ & Acute Myocardial Infarction \\
\hline C171288 & $\mathrm{F}$ & 94 & $\begin{array}{l}\text { Sup thyroid margins } \\
\mathrm{R} \text { greater horn } \\
\mathrm{L}+\mathrm{R} \text { post thyroid margins }\end{array}$ & $\begin{array}{l}\text { Abrupt angles } \\
\text { Incomplete fusion } \\
\text { Linear crease }\end{array}$ & Acute Myocardial Infarction \\
\hline $\mathrm{C} 171258$ & $\mathrm{~F}$ & 76 & $\begin{array}{l}\text { Laminae } \\
\mathrm{R}\end{array}$ & $\begin{array}{l}\text { Fragmentary ossification } \\
\text { Triticeous cartilage }\end{array}$ & Heart failure \\
\hline L172291 & M & 86 & $\begin{array}{l}\mathrm{L}+\mathrm{R} \\
\mathrm{L} \text { post thyroid margin }\end{array}$ & $\begin{array}{l}\text { Triticeous cartilages } \\
\text { Linear crease }\end{array}$ & Adenocarcinoma of lung \\
\hline S170345 & M & 86 & $\begin{array}{l}\mathrm{L}+\mathrm{R} \\
\text { Laminae }\end{array}$ & $\begin{array}{l}\text { Triticeous cartilages } \\
\text { Fragmentary ossification }\end{array}$ & Myeolodysplastic Syndrome \\
\hline S171263 & M & 67 & L greater horn & Incomplete fusion & Leukaemia \\
\hline S170405 & M & 87 & $\begin{array}{l}\mathrm{L}+\mathrm{R} \\
\text { Sup margin ant laminae }\end{array}$ & $\begin{array}{l}\text { Triticeous cartilages } \\
\text { Fragmentary ossification }\end{array}$ & Colon cancer \\
\hline
\end{tabular}


Open Access This article is distributed under the terms of the Creative Commons Attribution 4.0 International License (http:// creativecommons.org/licenses/by/4.0/), which permits unrestricted use, distribution, and reproduction in any medium, provided you give appropriate credit to the original author(s) and the source, provide a link to the Creative Commons license, and indicate if changes were made.

\section{References}

1. Office for National Statistics (2018) Homicide in England and Wales: year ending March 2017. https://www.ons.gov.uk/ peoplepopulationandcommunity/crimeandjustice/articles/ homicideinenglandandwales/yearendingmarch2017. Accessed 27 August 2018

2. Strack GB (2007) How to improve your investigation and prosecution of strangulation deaths. National Family Justice Centre Alliance, San Diego

3. Dunsby AM, Davison AM (2011) Causes of laryngeal cartilage and hyoid bone fractures found at postmortem. Med Sci Law. 51(2): 109-113. https://doi.org/10.1258/msl.2010.010209

4. Davison AM, Williams EJ (2012) Microscopic evidence of previous trauma to the hyoid bone in a homicide involving pressure to the neck. Forensic Sci Med Pathol. 8(3):307-311. https://doi.org/ 10.1007/s12024-012-9316-3

5. Kempter M, Ross S, Spendlove D, Flach P, Preiss U, Thali M, Bolliger S (2009) Post-mortem imaging of laryngohyoid fractures in strangulation incidents: first results. Leg Med. 11(6):267-271. https://doi.org/10.1016/j.legalmed.2009.07.005

6. Becker M, Leuchter I, Platon A, Becker CD, Dulguerov P, Varoquaux A (2014) Imaging of laryngeal trauma. Eur J Radiol. 83:142-152. https://doi.org/10.1016/j.ejrad.2013.10.021

7. Kettner M, Potente S, Schulz B, Knauff P, Schmidt PH, Ramsthaler F (2014) Analysis of laryngeal fractures in decomposed bodies using microfocus computed tomography (mfCT). Forensic Sci Med Pathol. 10(4):607-612. https://doi.org/10.1007/s12024-0149584-1

8. Fais P, Giraudo C, Viero A, Miotto D, Bortolotti F, Tagliaro F, Montisci M, Cecchetto G (2016) Micro computed tomography features of laryngeal fractures in a case of fatal manual strangulation. Leg Med. 18:85-89. https://doi.org/10.1016/j.legalmed.2016.01. 001

9. Thali MJ, Taubenreuther U, Karolczak M, Braun M, Brueschweiler W, Kalender WA, Dirnhofer R (2003) Forensic microradiology: micro-computed tomography (Micro-CT) and analysis of patterned injuries inside of bone. J Forensic Sci. 48(6):1336-1342

10. Baier W, Norman DG, Warnett JM, Payne M, Harrison NP, Hunt NC, Burnett BA, Williams MA (2017) Novel application of threedimensional technologies in a case of dismemberment. Forensic Sci Int. 270:139-145. https://doi.org/10.1016/j.forsciint.2016.11.040

11. Norman DG, Watson DG, Burnett BA, Fenne P, Williams MA (2017) The cutting edge- micro-CT for quantitative toolmark analysis of sharp force trauma to bone. Forensic Sci Int. 283:156-172. https://doi.org/10.1016/j.forsciint.2017.12.039

12. Fais P, Giraudo C, Viero A, Amagliani A, Viel G, Montisci M, Miotto D, Cecchetto G (2015) Identification of bullet entrance in different type of intermediate firearm wounds through microcomputed tomography analysis. J Forensic Radiol Imaging. 3(3): 147-152. https://doi.org/10.1016/j.jofri.2015.07.004

13. Cecchetto G, Giraudo C, Amagliani A, Viel G, Fais P, Cavarzeran F, Feltrin G, Ferrara SD, Montisci M (2011) Estimation of the firing distance through micro-CT analysis of gunshot wounds. Int J Leg Med. 125(2):245-251
14. Richards CS, Simonsen TJ, Abel RL, Hall MJR, Schwyn DA, Wicklein M (2012) Virtual forensic entomology: improving estimates of minimum post-mortem interval with 3D micro-computed tomography. Forensic Sci Int. 220(1):251-264. https://doi.org/10. 1016/j.forsciint.2012.03.012

15. Tsai A, McDonald AG, Rosenberg AE, Gupta R, Kleinman PK (2014) High-resolution CT with histopathological correlates of the classic metaphyseal lesion of infant abuse. Pediatr Radiol. 44(2): 124-140. https://doi.org/10.1007/s00247-013-2813-z

16. Baier W, Mangham C, Warnett JM, Payne M, Painter M, Williams MA (2019) Using histology to validate micro-CT findings of trauma in three post-mortem samples- First steps towards method validation. Forensic Sci Int. 297:27-34. https://doi.org/10.1016/j. forsciint.2019.01.027

17. Brunke O, Santillan J and Suppes A (2010) Preecise 3D dimensional metrology using high-resolution x-ray computed tomography $(\mu \mathrm{CT})$. In: Stock SR (ed) Proceedings of the SPIE, Volume 7804. [Online]. SPIE Digital Library. https://www.spie.org/Publications/ Proceedings/Volume/7804?\&origin_id $=x$ 4323\&start yea $r=$ 2010\&end year $=2010 \&$ start at $=41 \& S S O=1$. Accessed 17 March 2006

18. Kruth J-P, Bartscher M, Carmignato S, Schmitt R, De Chiffre L, Weckenmann A (2011) Computed tomography for dimensional metrology. CIRP Annals-Manufacturing Technology. 60(2):821842. https://doi.org/10.1016/j.cirp.2011.05.006

19. Lifton JJ, Malcolm AA, McBride JW, and Cross KJ (2013) The application of voxel size correction in X-ray computed tomography for dimensional metrology. 2nd Singapore International Nondestructive Testing Conference and Exhibition, 19-20 July 2013, Singapore

20. Welkenhuyzen F, Kiekens K, Pierlet M, Dewulf W, Bleys P, Kruth J-P, Voet A (2009) Industrial computer tomography for dimensional measurement: overview of influence factors and improvement strategies. In: Dirckx J, Buytaert J (eds) 4th International Conference on Optical Measurement Techniques for Structures and Systems. Belgium, Shaker, pp 401-410

21. Dettmeyer RB, Verhoff MA, Schütz HF (2014) Forensic medicine: fundamentals and perspectives. Springer, Heidelberg

22. Maxeiner H, Bockholdt B (2003) Homicidal and suicidal ligature strangulation- a comparison of the post-mortem findings. Forensic Sci Int. 137(1):60-66. https://doi.org/10.1016/S0379-0738(03) 00279-2

23. Naik SK, Patil D (2005) Fracture of hyoid bone in cases of asphyxial deaths resulting from constricting force round the neck. J Indian Academy Forensic Med. 27(3):149-153

24. Shaik MM, Chotaliya HJ, Modi AD, Parmar AP, Kalele SD (2013) A study of gross postmortem findings in cases of hanging and ligature strangulation. J Indian Academy Forensic Med. 35(1):6365

25. Raikos A, Paraskevas GK (2013) The thyroid foramen: a systematic review and surgical considerations. Clinical Anat. 26(6):700-708. https://doi.org/10.1002/ca.22234

26. Di Nunno N, Lombardo S, Costantinides F, Di Nunno C (2004) Anomalies and alterations of the hyoid-larynx complex in forensic radiographic studies. American J Forensic Med Pathol. 25(1):14 19. https://doi.org/10.1097/01.paf.0000113931.49721.e4

27. Naimo P, O’Donnell C, Bassed R, Briggs C (2013) The use of computed tomography in determining developmental changes, anomalies, and trauma of the thyroid cartilage. Forensic Sci Med Pathol. 9(3):377-385. https://doi.org/10.1007/s12024-013-9457-z

28. Maxeiner H (1999) Healed fractures of the larynx and lingual bone in forensic autopsy. Archiv fur Kriminologie. 203(5-6):175-183

29. Saternus K-S, Maxeiner H, Kernbach-Wighton G, Koebke J (2013) Traumatology of the superior thyroid horns in suicidal hanging- An injury analysis. Leg Med. 15(3):134-139. https://doi.org/10.1016/j. legalmed.2012.10.008 
30. Dang-Tran KD, Dedouit F, Joffre F, Rougé D, Rousseau H, Telmon N (2010) Thyroid cartilage ossification and multislice computed tomography examination: a useful tool for age assessment? $J$ Forensic Sci. 55(3):677-683. https://doi.org/10.1111/j.1556-4029. 2010.01318.x

31. Regulator FS (2017) Code of practice and conduct. Forensic Science Regulator, Birmingham
32. Cole SA (2012) Forensic science and wrongful convictions: from exposer to contributor to corrector. New Engl Law Review. 46(4): $711-736$

Publisher's note Springer Nature remains neutral with regard to jurisdictional claims in published maps and institutional affiliations. 